\title{
A CRÍTICA DE TRADUÇÕES NO BRASIL: \\ UM OLHAR SOBRE OS TRABALHOS DE AGENOR SOARES DE MOURA E GABRIEL PERISSÉ
}

Regysane Botelho C Alves é professora assistente da Universidade Federal do Maranhão e mestre em Letras - Estudos da Linguagem pela PUC-Rio. E-mail: regysane@gmail.com

\section{Resumo}

Este artigo apresenta o trabalho de críticas de traduções desenvolvido por Agenor Soares de Moura e Gabriel Perissé, destacando suas contribuições para o desenvolvimento dessa atividade no Brasil.

\begin{abstract}
This article presents Agenor Soares de Moura and Gabriel Perissé's works in translation criticism, highlighting their contributions to the development of this activity in Brazil.
\end{abstract}

\section{1) Introdução}

O estudo de crítica de traduções leva a descobrir que, especialmente no Brasil, a crítica de traduções é ainda um tema pouco explorado. Poucos são os estudos brasileiros que tratam centralmente da crítica de traduções; o que temos são apenas alguns trabalhos de pós-graduação (Battisti, 2000; Silva, 2001; Cardozo, 2004), alguns artigos publicados em revistas acadêmicas, e algumas considerações acerca desse tema espalhadas em estudos da tradução como os de Rosemary Arrojo e José Paulo Paes.

Além disso, no que diz respeito à prática, a crítica de traduções é quase inexiste no Brasil como prática sistematizada, ainda que o país conte com um vasto número de obras traduzidas disponíveis no mercado. E mais, segundo Silva, nos textos dos poucos críticos que analisam, comparam e avaliam traduções, "quase nenhum espaço é dedicado à reflexão sobre os critérios que determinam tais avaliações e à discussão do modo como efetuá-las" (2001, p.16).

Ainda assim, a prática propriamente dita de crítica de traduções, em especial das literárias, tem uma importante referência no trabalho que foi desenvolvido por Agenor Soares de Moura no suplemento literário de O Diário de Notícias; e mais recentemente nos artigos publicados por Gabriel Perissé na Revista Língua Portuguesa.

O primeiro publicou de setembro de 1944 a junho de 1946 vários artigos de crítica de tradução em uma seção intitulada "À Margem das Traduções" (Barroso, 2003); o segundo vem assinando a coluna "Versão Brasileira" desde setembro de 2005.

Moura já é bastante reconhecido entre os tradutores pela grande importância de seu trabalho, tanto que José Paulo Paes questiona

por que essa iniciativa pioneira não teve continuadores, principalmente em nossos dias, onde o enorme incremento do número de títulos traduzidos e o nível tantas vezes insatisfatório das traduções está a exigir, mais que nunca, fiscais capazes de ajudar os leitores a distinguir o joio do trigo em meio à nossa copiosa produção editorial (1990, p.117-118). 
Por outro lado, apesar de mais recente, Perissé já recebeu algumas manifestações de reconhecimento publicadas na seção "Cartas" da revista. Dentre estas, destaco a da tradutora e estudiosa Ivone C. Benedetti que teve sua opinião publicada em novembro de 2007: "É confortador saber que um estudioso de seu quilate tem publicado artigos sérios sobre tradução, assunto pelo qual poucos se interessam fora de um âmbito acadêmico restrito ou do círculo dos profissionais diretamente ligados à atividade" (2007, p.6).

\section{2) Os desafios da crítica de traduções}

A pouca ocorrência de críticas publicadas ocorre também porque a tarefa de criticar traduções não é simples. Principalmente porque lida com a análise e avaliação de uma prática que não se permite definir. Para Umberto Eco, ao respondermos a pergunta

O que quer dizer traduzir? A primeira e consoladora resposta gostaria de ser: dizer a mesma coisa em outra língua. Só que, em primeiro lugar, temos muitos problemas para estabelecer o que significa "dizer a mesma coisa" e não sabemos bem o que isso significa [...]. Em segundo lugar, porque, diante de um texto a ser traduzido, não sabemos também o que é a coisa. E, enfim, em certos casos é duvidoso até mesmo o que quer dizer dizer (2003, p.9).

Assim a prática de criticar traduções precisa criar parâmetros de avaliação que ajudem os leitores a entender um pouco mais o processo de traduzir e a decidir o que consideram uma boa tradução. Na verdade, a crítica de traduções é o meio que permite ao leitor perceber o trabalho do tradutor e sua qualidade.

Infelizmente, no que tange a avaliar traduções, "apenas alguns jornais e revistas publicam com certa frequência 'crítica' de traduções. O que lemos em geral são resenhas de traduções que visam dar ao leitor alguma identificação sobre o teor dos últimos lançamentos" (Lia Wyler, 2003, p.200). Isso porque a riqueza e a complexidade da crítica de traduções "se constitui justamente a partir do cruzamento e da tentativa de colocar em diálogo os espaços de reflexão sobre a crítica, tradução e literatura" (Cardozo, 2007, p. 208), exigindo assim, que seu executor tenha qualificações especiais.

Para José Paulo Paes,

além de culta literária e conhecimento de línguas o aferidor deve ter certa familiaridade com os procedimentos tradutórios seja pela sua prática, seja pela leitura frequente de traduções de nível, por via das quais tenha podido adquirir uma noção da natureza dos limites do traduzir (1990, p. 116).

Para Paes (1990), são os tradutores os profissionais que mais bem reúnem essas características: 
Na opinião de Ivone Benedetti, a função do crítico de traduções exigiria alguém que entenda de tradução. Alguém que conheça as duas línguas! Mas não só: alguém que escolha caminhos e atalhos que levam de uma à outra. Mas não só: alguém que conheça a obra original, seu autor. Mas não só... alguém que conheça estilística... E assim por diante. Não é fácil (2005, p.72).

Entretanto, as críticas que são produzidas em um contexto jornalístico normalmente não têm "como sujeito dessa prática um profissional especializado na área e voltado exclusivamente para tal atividade" (Cardozo, 2007, p.214). Esses profissionais podem ser oriundos das áreas de Literatura, Filosofia e Artes Cênicas, entre outras. Nesse contexto, é difícil perceber os critérios e os parâmetros usados para discutir a qualidade das traduções. Principalmente porque esse tipo de mídia impõe ao crítico uma limitação de espaço e tempo para a produção do texto final. Talvez por isso haja aí uma tendência para publicarem-se resenhas das obras e não críticas de sua tradução. Além disso, os textos se destinam a um público variado e não apenas a profissionais e estudiosos da tradução.

Entretanto, é preciso reconhecer que um posicionamento em relação à qualidade das traduções não é tarefa fácil, independente da formação profissional do crítico, já que são várias as perspectivas que permitem situar a qualidade de uma dada tradução em diferentes pontos de uma escala de valor. Nesse sentido, é possível encontrar alguns discursos teóricos que se posicionam quanto aos elementos que comporiam essa desejada qualidade.

$\mathrm{Na}$ área de tradução, os conceitos de equivalência e fidelidade — os quais possuem uma relação muito estreita entre si - são, provavelmente, os mais referidos nas críticas a fim de aferirem a qualidade do texto traduzido. Ao discorrer sobre tradução, "equivalência" é o "termo usado por vários escritores para descrever a natureza e amplitude das relações existentes entre textos ou unidades linguísticas menores da língua-fonte (LF) e da língua-meta (LM)" (Shuttleworth \& Cowie, 1999, p.49). Já "fidelidade" é o termo usado para "descrever em que medida um TT [texto traduzido] pode ser considerado um bom representante de um TO [texto original] de acordo com certo critério". Nesse sentido, "tradicionalmente uma tradução fiel é considerada aquela que apresenta uma forte semelhança [ou seja, equivalência] com o seu TO normalmente em termos ou da aderência LITERAL ao significado fonte ou da comunicação eficiente do 'espírito' do original” (Shuttleworth \& Cowie, 1999, p.47).

Contemporaneamente, estudiosos pós-estruturalistas defendem que não há fidelidade a um original e sim à interpretação que dele se faz e à concepção que se tem do processo e produto tradutórios. Para esses estudiosos, segundo o poeta, tradutor, crítico e professor de tradução Paulo Henriques Britto,

os textos não possuem significados estáveis que correspondam a intenções que seus autores tivessem em mente ao escrevê-los (se é que os autores têm controle total sobre suas intenções); só temos acesso a nossas próprias leituras dos textos. Assim, quando 
dizemos que uma dada tradução é fiel ao original, estamos dizendo apenas que nossa leitura dessa tradução é fiel à nossa leitura do original; nada podemos afirmar sobre os textos em si (2006, p.239).

Rosemary Arrojo, por exemplo, defende que tradutores, leitores e, consequentemente, críticos são fiéis não ao texto "original", mas àquilo que acreditam ser o original e a sua concepção de tradução (2005, p.44). Entretanto, a própria Arrojo diz, mais adiante em seu texto, que ainda que se conclua

que toda tradução é fiel às concepções textuais e teóricas da comunidade interpretativa a que pertence o tradutor e também aos objetivos que se propõe, isso não significa que caem por terra quaisquer critérios para a avaliação de traduções $(2005$, p.45).

Britto argumenta que, justamente por haver essa possibilidade de múltiplas interpretações, "é necessário analisar, discutir e tentar estabelecer consensos, ainda que parciais" (2006, p.240-241). E completa, afirmando:

ainda que não haja consenso absoluto, e ainda que cada um de nós faça seus julgamentos com base em seus próprios pressupostos, é possível utilizar o discurso racional para fazer avaliação e tecer considerações em torno de traduções, fazendo referência a certas propriedades dos textos traduzidos com relação às quais há um certo grau de acordo entre um bom número de pessoas envolvidas nas atividades de traduzir (Britto, 2006, p.252).

Para eles, a tarefa do tradutor - e por consequência a qualidade das traduções deve ser discutida a partir de duas perspectivas, que podem ser apresentadas da seguinte forma: "[o]u o tradutor deixa o autor em paz e leva o leitor até ele; ou deixa o leitor em paz e leva o autor até ele" (Schleiermacher, 2001, p.43).

Para Schleiermacher, esses movimentos de afastamento ou aproximação do estrangeiro são bastante distintos. No primeiro caso, "o tradutor está empenhado em substituir, através de seu trabalho, a compreensão da língua de origem, que falta ao leitor" (2001, p.43). Nesse processo de aproximação, o tradutor

tentará transmitir aos leitores a mesma imagem, a mesma impressão que ele próprio teve através do conhecimento da língua de origem da obra, de como ela é, e tenta, pois, levá-los à posição dela, na verdade estranha para eles (Schleiermacher, 2001, p.43 e 45)

O segundo caso apresenta um método que

não exige nenhum empenho e esforço de seu leitor, que por magia lhe transfere o autor estrangeiro para seu presente imediato e que quer lhe mostrar a obra assim como ela seria, se o autor mesmo a tivesse escrito originalmente na língua do leitor (Schleiermacher, 2001, p.63). 
Para Berman, o "tradutor que traduz para o público é levado a trair o original, preferindo o seu público, a quem também trai, já que apresenta uma obra 'arrumada"” (2007, p.65). Para ele, a atitude que tenta "[e]mendar as estranhezas de uma obra para facilitar sua leitura acaba por desfigurá-la, e, portanto, enganar o leitor a quem se pretende servir" (Berman, 2007, p.66). Assim, na atividade tradutória o profissional encontra-se na tensão entre "servir à obra, ao autor, à língua estrangeira (primeiro senhor) e de servir ao público e à língua própria (o segundo senhor)" (Berman, 2002, p.15). Como pode-se interpretar de suas afirmações, Berman considera uma má tradução aquela que, "geralmente sob pretexto de transmissibilidade, opera uma negação sistemática da estranheza da obra estrangeira" (2002, p.18). Esse tipo de tradução, chamada por ele de etnocêntrica, "tende a destruir o sistema do original" (Berman, 2002, p.20).

Segundo Venuti, em culturas associadas aos Estados Unidos e ao Reino Unido, um

texto traduzido, quer seja prosa ou poesia, ficção ou não ficção, é considerado aceitável pela maioria dos editores, resenhistas e leitores quando ele é fluente, quando a ausência de qualquer peculiaridade linguística ou estilística faz com que ele pareça transparente, dando a impressão que reflete a personalidade ou a intenção do escritor estrangeiro ou o significado essencial do texto estrangeiro - a impressão, em outras palavras, de que a tradução não é de fato uma tradução, mas o "original" (1995b, p.1).

Essa postura, chamada por Venuti de domesticadora, é veementemente condenada por ele, já que ela promove um apagamento do tradutor e de seu trabalho, causando o que ele chama de "invisibilidade do tradutor", que seria a causa da desvalorização desse profissional e de sua atividade. Aliás, para este autor, um texto traduzido "não pode ser confundido nem com o texto na língua-fonte nem com um texto originalmente escrito na língua-meta”. Para ele,

a tradução deve ser vista como um tertium datum, que "soa estrangeiro" para o leitor, mas tem uma aparência opaca [para que deixe] visível a intervenção do tradutor, seu confronto com a natureza alienígena do texto estrangeiro" (Venuti, 1995a, p.118).

Disso se pode inferir que para Venuti uma boa tradução é aquela em que o tradutor deixa marcas, em que ele revela a natureza estrangeira do texto.

Vale ressaltar que as avaliações de Berman e Venuti foram feitas em contextos específicos de culturas que tendem a valorizar o que é nacional, em detrimento do estrangeiro. Berman desenvolve a sua argumentação se opondo à tradição francesa de modificar os textos estrangeiros de tal modo que parecessem originalmente escritos no francês, movimento que criou as chamadas "belas infiéis"; Venuti se coloca contra a dominação imperialista anglo-americana que apaga o estrangeiro, causando a invisibilidade da tradução. Por outro lado, estudiosos da tradução que avaliam a 
qualidade dos textos traduzidos em uma cultura "invadida" por ingredientes estrangeiros talvez percebam uma tradução estrangeirizadora (ou antietnocêntrica) como uma forma de "colonização".

\section{3) A contribuição de Agenor Soares de Moura}

Como já apresentado na introdução deste trabalho, a crítica de traduções literárias no Brasil não pode ser considerada uma novidade na esfera de trabalho de nossos tradutores uma vez que, além dos trabalhos fixos e sistemáticos de Moura e Perissé, alguns movimentos independentes e esporádicos de crítica também podem ser encontrados ao longo de nossa história literária.

Vários escritores como Augusto Meyer, João Cabral de Melo Neto e Manuel Bandeira, tradutores de várias obras literárias, segundo José Paulo Paes, faziam considerações a respeito da qualidade de traduções brasileiras. Paes também destaca os trabalhos críticos de Mário de Andrade e Sérgio Milliet, que "podem ser vistos em Território da tradução, antologia organizada por Iumna Maria Simon” (1990, p.116), como dois bons exemplos de crítica de traduções realizadas nesse período.

Além dessa indicação de Paes, também pode-se destacar o nome de Paulo Rónai. Alguns dos textos publicados por esse importante pensador da tradução no Brasil, em particular no seu livro Escola de Tradutores (1987), podem ser considerados excelentes exemplos de crítica de tradução.

Aqui, daremos destaque às críticas realizadas por Agenor Soares de Moura professor, crítico e tradutor que viveu quase toda a sua vida em Barbacena - que desenvolveu um significativo trabalho de crítica de traduções na década de 1940. Suas críticas foram publicadas semanalmente no Diário de Notícias do Rio de Janeiro, em uma coluna dominical intitulada "À margem das traduções". Hoje, os artigos de Moura podem ser lidos no livro À margem das traduções (2003), editora Arx, organizado por Ivo Barroso e apresentado por Paulo Rónai.

Moura foi convidado a contribuir com o jornal após ter respondido a uma solicitação feita pelo então crítico literário do jornal carioca, Guilherme Figueiredo. Este, após se indignar com a péssima qualidade da tradução de $O$ livro de Jó, feita por Lúcio Cardoso, escreveu um artigo no qual "acusava os editores brasileiros de incapazes de julgar os originais e de selecionar os tradutores" (Barile, 2004, p.8) e "convidou seus leitores a ajudar a melhorar o nível das traduções, denunciando erros e infidelidades que topassem nas suas leituras estrangeiras" (Rónai, 2003, p.10).

A carta-resposta de Moura surpreendeu Figueiredo pela grande erudição e conhecimento de línguas estrangeiras por parte do professor. Moura conseguia avaliar com competência traduções do inglês, alemão, francês e espanhol.

Com tal erudição, Moura inspirou a criação da seção de críticas de obras traduzidas, que passaram a ser assinadas por C.T. (crítico de traduções), pseudônimo 
criado por Figueiredo para protegê-lo, já que aquela não seria uma tarefa fácil, especialmente porque o "esquema das editoras era simples: para os grandes nomes da literatura mundial, eram convocados consagrados escritores de literatura brasileira" (Barile, 2004, p.9) que não se sentiriam muito a vontade em terem a qualidade de seus textos traduzidos questionada - mesmo que alguns trabalhos fossem somente assinados por eles, não traduzidos, tarefa que entregavam a outro profissional.

Cardozo descreve o trabalho de Moura como pioneiro e expoente da crítica de tradução literária no Brasil, mas esclarece que

seus textos críticos são marcados quase que exclusivamente pela discussão do detalhe, pelo flagrante pontual do gesto tradutório - quase sempre do gesto equívoco - , sem discutir as empreitadas tradutórias como resultado de um projeto maior de tradução, nem ponderar a relevância, para o todo da obra traduzida, dos equívocos anunciados (2007, p.215).

Esse comentário deve-se ao tipo de crítica desenvolvida por Moura, a qual consistia basicamente em observações a respeito de interpretações incorretas especialmente quando se tratavam de falsos cognatos ou falsos amigos; de traduções feitas em decalque que reproduziam em português as características e expressões próprias do idioma estrangeiro; e de erros na utilização do idioma pátrio pelo tradutor, tanto no que diz respeito à correta utilização das palavras quanto à correção gramatical. Essas observações sempre apresentavam soluções alternativas para os problemas identificados. Não raro são encontradas em seus artigos palavras como "defeito", "imperfeições" e "desacertos" ao tratar das escolhas lexicais dos tradutores.

Diante desse quadro, poder-se-ia considerar "negativa" ou "destrutiva" a crítica de Moura. No entanto, na opinião de Cardozo (2007), o padrão crítico que Moura adota reflete a sua preocupação em cuidar da "dimensão linguística da obra traduzida"; suas críticas, ainda conforme Cardozo, "demonstram propriedade e consistência, são elegantes, põem sempre a nu as justificativas de cada reparo crítico e, não raro, oferecem soluções alternativas" (2007, p.215). Assim, ao contrário do que possa parecer à primeira vista, prevalecia na coluna de Moura um caráter pedagógico, porque ele estava também preocupado em recomendar formas de evitar os erros comuns nas traduções que criticava (Barroso, 2003, p.15).

Por exemplo, no texto publicado em 24/09/1944, dedicado à tradução de Pride and prejudice, de Jane Austin, feita por Lúcio Cardoso, Moura declara que pelo que se lê na tradução "não se pode dizer que [o tradutor] morra de amores pela correção gramatical" (Moura, 2003, p.22). Nesse texto, o crítico aproveita para explicar ao leitor que

o inglês possui, dentre a farta messe de termos de origem latina, alguns que, ao lado da significação ou significações com que passaram para a nossa língua, têm outra ou outras estranhas ao nosso uso. Constituem eles o que os autores franceses, que se ocupam da língua inglesa, chamam de faux amis ou les mots traîtres. Falsos amigos, sim, porque 
parecendo na forma exterior com vocábulos nossos, possuem não raro acepções bem diferentes das que os nossos têm (Moura, 2003, p.23).

Somente depois dessa explicação, ele apresenta alguns trechos da tradução do texto de Austin em que Lúcio Cardoso traduzira incorretamente alguns falsos amigos. Aliás, esse era um tema que muito inquietava Moura; ele dedicou o artigo publicado em 08/10/1944 apenas a essas palavras, armadilhas para tradutores desatentos e despreparados.

No artigo seguinte, publicado em 15/10/1944, Moura critica Érico Veríssimo por deixar-se "contaminar docemente do idioma inglês, comprometendo de leve o nosso falar, em vários trechos" da obra Gato preto em campo de neve. Esse é um dos muitos momentos em que Moura critica a contaminação da língua portuguesa por estrangeirismos, demonstrando o quão caro lhe era o nosso idioma e como se incomodava que tão distinto autor cometesse tantos anglicismos. Essa atitude protecionista de Moura estava em sintonia com o movimento literário e cultural oficialmente iniciado em 1922 com a Semana de Arte Moderna, que se preocupava em valorizar e proteger os bens culturais brasileiros, em particular o nosso idioma "brasileiro".

Indicando uma preocupação com o ofício do tradutor, o artigo de 08/10/1944, que tematiza os falsos cognatos, mostra a falta de cuidado de muitos em relação a esse ofício, tratando especificamente das dificuldades e desafios de ser tradutor.

Já no artigo de 22/10/1944, ele denuncia os perigos das traduções indiretas:

E a propósito de versão portuguesa, feita de uma versão francesa de livro original alemão, notava um atilado leitor que tais adaptações de uma adaptação constituem um tipo de obra desnatada e dessorada, obra em que o pensamento primitivo do autor já anda tão mudado com a longa caminhada que o próprio autor não o reconheceria sem dificuldade (Moura, 2003, p.31).

O trecho a seguir, marcado por fina ironia, é mais um exemplo de como ele buscava dialogar com os leitores, sem abandonar o aspecto didático de seus comentários:

Uma leitora estranhou no livro de Elinor Glynn, The price of things, traduzido por Manuel Bandeira com o título Tudo se paga, a expressão "olhos calmucos". Podemos responder que talvez não tenha achado a palavra devido a diferenças ortográficas. No Larousse Illustré encontrará 'Kalmouks', povo da Mongólia, que tem “...lex yeux bridés", isto é, apertados e oblíquos, como os têm os povos de raça amarela. Será isso? (Moura, 2003, p.106).

Mas, apesar de toda a preocupação com a qualidade das traduções brasileiras, o trabalho de Moura na coluna tinha apenas o objetivo de criticar as más traduções, 
provando que determinado livro fora mal traduzido e oferecendo sugestões para melhorá-lo (Barroso, 2003, p.17).

Não era, portanto, preocupação dele, exercer uma crítica como médium de reflexão, como prática de exploração das dimensões culturais, literárias, ideológicas e políticas da tradução, ou seja, como geradora da base ontológica de práticas poéticas, críticas e tradutórias de sua época (Cardozo, 2007, p.216).

Desse modo, segundo Cardozo, ainda que os pressupostos e a prática de Moura possam ser considerados legítimos para a década de 1940, "em vista do contexto atual dos estudos da linguagem, da literatura e da tradução, uma prática crítica fundada nesses mesmos pressupostos não pode ser considerada, senão, como ingênua ou insuficiente" (2007, p.216).

Para Ivo Barroso, nessa época, o trabalho desenvolvido por Moura contribuiu para mudar um pouco a consciência que se tinha do trabalho do tradutor, pois os "leitores passaram a valorizar aqueles profissionais eficientes que eram até então desconhecidos e anônimos" (apud Barile, 2004, p.9).

Cabe lembrar que, antes do editor Guilherme Figueiredo e do crítico Agenor Soares de Moura,

em 1939, Mário de Andrade já havia chamado a atenção para a situação do ofício do tradutor e escrevia no mesmo Diário de notícias: "Tradução é necessariamente ato de amor ou de pragmática social - o que vale dizer ainda amor. Mas entre nós está se tornando a última tábua de salvação para os desempregados. Posso ter muito respeito, muita inquietação pelos desempregados, mas traduzir não é ofício de piedade (Barile, 2004, p.9).

Infelizmente, após cerca de dois anos de existência, a coluna de Moura foi encerrada. Isso ocorreu porque as editoras não enviavam seus lançamentos para o jornal, já que não tinham interesse em passar pela rigorosa avaliação do crítico que não conseguiu manter por muito tempo a compra, com o próprio dinheiro, dos originais e traduções necessários ao seu trabalho.

A partir de então, a avaliação de traduções na mídia tem sido feita em resenhas que são publicadas em cadernos literários de jornais ou mesmo em revistas, nas quais os comentários, de um modo geral, tratam da obra como se ela não fosse uma tradução ou, quando muito, referem-se a ela de forma breve e superficial. Segundo Silva (2001, p.5), que estudou as resenhas de tradução publicadas na década de 1990 no caderno "MAIS!" do jornal Folha de São Paulo, ainda que em seu corpus haja um número significativo de textos que trazem no título a palavra "tradução", na maioria deles, o resenhista limita-se a falar da obra e do autor.

\section{4) O momento da "Versão Brasileira"}


Em agosto de 2005, foi publicada a primeira edição da Revista Língua Portuguesa - periódico destinado a apresentações de questões relativas à língua portuguesa, em especial a brasileira, nas mais diversas áreas dos estudos linguísticos, literários e pedagógicos - que vem apresentando desde então a seção "Versão Brasileira", que passou a ser assinada por Gabriel Perissé a partir do mês de setembro daquele ano. Essa coluna vem apresentando um trabalho crítico interessante, com comentários que permitem entrever um pensamento que incorpora concepções contemporâneas de tradução, sem banalizar a prática dessa atividade, reconhecendo as dificuldades que ela implica.

Além disso, é interessante o modo como o crítico dialoga com outras vozes da área de Tradução e de Literatura, apresentando opiniões e informações dadas por outros críticos, teóricos e tradutores. Em uma coluna, ele cita Ortega y Gasset ao declarar que ser tradutor "é exercer tarefa literária específica, abrindo caminhos para leitores que não tenham acesso a outros idiomas" (Perissé, 2006a, p.59).

Nos comentários do crítico também podem ser encontrados fragmentos nos quais ele destaca a importância da própria crítica de traduções. Na coluna publicada em março de 2007 sobre A República, de Platão, Perissé afirma: "Melhor ainda, porém, é pensar com rigor e criatividade a partir de uma boa tradução! Daí a necessidade de aferir a qualidade das versões de que dispomos, remontando ao grego, e comparando essas versões entre si” (Perissé, 2007b, p.61).

A coluna mantida por Perissé pode ser dividida, de modo geral, em duas partes: uma voltada para o original e seu autor, e outra voltada para a tradução, suas peculiaridades e os tradutores. Na primeira parte, são apresentadas características da obra original e, normalmente, informações biográficas e de estilo do autor. Na segunda parte, ele apresenta diferentes versões brasileiras, seus respectivos tradutores, editoras e data de publicação (em alguns casos também cita traduções feitas em outros países); trata dos projetos e dos estilos dos tradutores; e oferece em uma tabela um trecho do original e suas traduções, para a apreciação dos leitores, a qual serve de base para seus comentários a respeito das escolhas tradutórias.

Todas essas informações são apresentadas de forma leve e atraente em um texto que sempre convida o leitor a também ser crítico, inclusive com a possibilidade de discordar das afirmações feitas por Perissé. Essa atitude pode ser inferida, por exemplo, do convite que ele faz ao leitor no artigo de "De Ulysses a Ulisses":

Façamos, apenas a título de curiosidade — nada substituirá a dor e a alegria de navegar pessoalmente o mar de palavras joyceano - uma comparação entre o texto original (...) e o trabalho de Houaiss e Bernardina, saboreando as soluções obtidas e sonhando com outras (imaginar traduções não paga imposto!), a partir do sempre desafiante estilo do autor (Perissé, 2005, p.60). 
A influência de sua formação acadêmica na área de Literatura se faz notar na qualidade das informações que Perissé apresenta sobre cada original e seu autor. Por vezes, essas informações ocupam quase toda a coluna, deixando os comentários às traduções apenas para as tabelas que exibem os trechos da obra e suas traduções.

Entretanto, com as informações que veicula, o crítico consegue mais do que simplesmente apresentar cada obra; com essas informações ele consegue situar o leitor em relação a aspectos que não somente marcam o original, mas também influenciam as traduções.

As informações sobre a vida e a obra do autor normalmente iniciam a coluna e podem ser mais ou menos detalhadas. As informações sobre a obra variam consideravelmente, mas, quase sempre, giram em torno da temática, da narrativa e do personagem principal. A descrição da narrativa pode ser acompanhada de possíveis interpretações da intenção do autor e de esclarecimentos sobre o seu estilo.

Os comentários a respeito das traduções e dos tradutores ocupam, normalmente, a segunda parte da coluna e as tabelas nas quais os trechos do original e das traduções são exibidos para que o leitor possa cotejá-los.

O crítico sempre apresenta o nome dos tradutores, as editoras e as datas das traduções. Em caso de traduções esgotadas ou fora de catálogo, esse fato também é mencionado, como no caso dos 17 volumes de A Comédia Humana (da Editora Globo), sob responsabilidade de Paulo Rónai. Ele também destaca a ocorrência de várias traduções, às vezes em um curto espaço de tempo, de uma mesma obra, como é o caso de The strange case of Dr. Jekyll and $M r$. Hyde ( $O$ médico e o monstro), escrito pelo escocês Robert Louis Stevenson em 1886, para o qual há nove versões no Brasil.

Algumas vezes, ele faz referência a traduções estrangeiras junto às considerações que faz às traduções indiretas. Estratégia que considera legítima quando feita com "transparência e competência" como o faz Anah de Melo Franco, que traduziu Utopia utilizando-se "não do original em latim, mas de uma edição francesa da prestigiosa Albin Michel", mais tarde revisada pelos editores a partir de traduções inglesas (Perissé, 2006c, p.61).

Quanto aos tradutores, Perissé não se contenta em dar apenas os seus nomes. O caso de maior destaque é a coluna de maio de 2006, dedicada ao trabalho de José Paulo Paes, tradutor e poeta que para Perissé foi um dos responsáveis por "fazer da tradução brasileira um gênero literário" (2006a, p.58). No caso de Paes, as informações incluem referência a seu livro Tradução: a ponte necessária (Ática, 1990); e a seus vários prefácios e apresentações de traduções; além de várias obras traduzidas por ele - como a sua participação na equipe de tradutores do Cours de linguistique générale (Curso de linguística geral), de Ferdinand de Saussure. Dentre as várias traduções realizadas por Paes, Perissé escolheu, para comentar, um trecho da obra $A$ vida e as opiniões do cavaleiro Tristram Shandy, do irlandês Laurence Sterne. Sobre esse trabalho de Paes, Perissé declara o seguinte: 
Paulo Paes, seguindo seu critério de respeitar ao máximo a fisionomia e idiossincrasias do texto original, conservou as numerosas extravagâncias e ousadias sintáticas e tipográficas, fazendo soar aos ouvidos brasileiros e portugueses, sempre que possível, as aliterações e outras "brincadeiras" estilísticas do autor (Perissé, 2006a, p.60).

Outra coluna com significativo destaque aos tradutores é a que faz a crítica das traduções de Ask the dust (Pergunte ao pó), de John Fante, publicada na revista de junho de 2007. Paulo Leminski e Roberto Muggiati são apresentados com suas peculiaridades de escritores e tradutores. Além disso, a eles é dada voz quando são apresentados trechos da introdução à tradução feita por Leminski e de uma entrevista dada por Muggiati a respeito dessa sua tradução:

Leminski, na introdução que faz à sua tradução, confidencia que se surpreendeu com o "híbrido de prosa e poesia" de Pergunte ao pó. Surpresa que certamente o agradou. Muggiati, por sua vez, numa entrevista ao jornalista Dodô Azevedo, registrou que traduzir o título do livro por Pergunte à poeira "não teria a mesma poesia de Pergunte ao pó" (Perissé, 2007e, p.60).

Quando é o caso, ele cita obras que o tradutor tenha escrito como autor. Por exemplo, sobre os tradutores do conto Une passion dans le desért é informado o seguinte:

A edição disponível (Paulus, 1988) traz a assinatura da tradutora Lúcia Machado de Almeida, falecida em 2005, irmã do escritor Aníbal Machado e autora de vários livros para crianças e jovens (quem não se lembra de $O$ Escaravelho do Diabo?). Por essa tradução, recebeu um prêmio da Associação Paulista de Críticos de Artes. Esse mesmo conto já fora traduzido pelo poeta Mário Quintana (Perissé, 2006b, p.56, grifo nosso).

Além desse tipo de informação biográfica, há também informações sobre o estilo dos tradutores. Por exemplo, para Perissé, a tradução feita por Houaiss do Ulysses (Ulisses), de James Joyce, possui características ("cerebral", "rebuscada") que estão "presentes no estilo do próprio tradutor" (2005, p.58).

No que tange ao projeto de tradução, ele é abordado em vários momentos. No caso de Monteiro Lobato, isso é feito mais detalhadamente:

Monteiro Lobato, cumprindo seu projeto editorial, traduziu/adaptou Alice em 1931. Em nome desse projeto, driblou grandes e pequenas dificuldades, mais preocupado em situar Alice no mundo do brasileiro do que em situar a este no mundo de Alice (Perissé, 2006e, p.63).

Finalmente, Perissé destaca interferências mais evidentes, como, por exemplo, a de Cruz Teixeira, tradutor de As Viagens de Gulliver que se permitiu algumas omissões, por crer que "é permitido ao tradutor ignorar palavras e trechos do original" (Perissé, 2006i, p.60). Há também casos como o de Éverton Ralph, tradutor de Frankenstein, que 
segundo Perissé, "incluiu, por sua conta e risco, a frase "malgrado as dimensões incomuns', com referência aos braços e pernas do monstro" (2007g, p.50).

Como pode ser percebido por esta última citação, o crítico não se agrada de inserções, omissões e/ou alterações feitas pelos tradutores.

No que foi descrito até aqui é possível perceber uma clara distinção entre os trabalhos de Perissé e Moura, pois aquele se preocupa em fazer uma contextualização da obra e sua(s) tradução(ões) que, a meu ver, busca explicar o fenômeno da tradução para o leitor da crítica, buscando garantir um diálogo com seus leitores e não apenas com os tradutores avaliados. Isso não quer dizer, entretanto, que ele não se preocupe com uma avaliação mais linguística das traduções.

Mas ele faz isso de um modo mais direto, discutindo as escolhas dos tradutores de forma mais ampla e contextualizada, incluindo os mais diversos aspectos envolvidos no processo de cada tradução. Em algumas edições da coluna, há discussões sobre um vocábulo cuidadosamente escolhido pelo crítico no contexto da obra, que pode tratar-se do título, do nome dado pelo autor a um personagem, ou outro termo que revele algo significativo da obra.

Um bom exemplo disso está na coluna publicada em março de 2007, na qual Perissé discute a complexidade da tradução do título de $A$ república, que em grego é

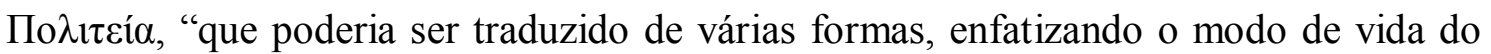
cidadão ( $\pi$ o $\lambda$ í $\varepsilon \varsigma \varsigma$ ), ou o modo de governar a cidade ( $\pi$ ó $\lambda ı \varsigma$ ) (Perissé, 2007b, p.60). Ele sugere como alternativa interessante o título "A Arte de Governar com Justiça", e informa que o título atual foi inspirado no diálogo De Re Publica, de Cícero, "embora seu sentido metafórico de 'corpo social' não corresponda exatamente ao que expressa Пo $\lambda \imath \varepsilon \varepsilon i ́ \alpha "$. O crítico conclui informando que "[q]uanto à acepção atual de 'república' como Estado não monárquico, nada tem a ver com o significado primitivo" (Perissé, 2007b, p.61).

Dentre as escolhas tradutórias discutidas pelo crítico, há os casos considerados por ele como erros: a tradução de "spéculateur" por "domador", feita por Lúcia Machado, seria um desses casos; Perissé aceita a de Mário Quintana, que traduz essa palavra por "especulador" (2006b, p.57). Para ele, também está incorreta a tradução de "mantenere la fed" por "conservar a fé", feita por Olívia Bauduh na obra $O$ príncipe, pois permite uma "leitura equivocada de que convém ao príncipe a fé religiosa" (Perissé, 2008d, p.59). Apesar de suas avaliações, Perissé não costuma ponderar sobre a relevância dos erros ou equívocos dos tradutores para o todo da tradução.

O problema da contaminação da tradução pela língua do original é também explicado por Perissé ao leitor:

Com respeito à colocação do adjetivo "curioso", Heloisa Jahn o antepõe - "curioso leitor" - , seguindo o original. Carmen Vera o pospõe - "leitor curioso" - , mas os resultados são desiguais. Aos nossos ouvidos, "leitor curioso" é a forma natural de 
identificar alguém movido pela curiosidade. Já "curioso leitor" soa de modo afetado e arcaizante (Perissé, 2008c, p.57).

Mostrando também como essa contaminação pode ser prejudicial para a clareza da tradução, como no caso da tradução de Sérgio Molina para um trecho de Dom Quixote:

No primeiro parágrafo, "voto a tal" é uma locução interjetiva muito própria do idioma espanhol. Manifesta aborrecimento e envolve ameaça. Traduzi-la ao pé da letra pouco ou nada significa para o leitor brasileiro, sobretudo o do século XXI. No segundo parágrafo, o tradutor tende a reproduzir literalmente, em português, o que está no original. "Apartando-se à parte” é uma opção desse tipo (Perissé, 2007a, p.60).

A fidelidade ao autor do original, suas ideias e estilo é uma constante nos julgamentos realizados por Perissé na "Versão Brasileira". Para ele, uma boa tradução abre "caminhos para leitores que não tenham acesso a outros idiomas, trabalhando com fidelidade criativa ao original, em sintonia com a língua para a qual o texto é vertido" (Perissé, 2006a, p.59). Perissé considera que cabe aos tradutores "acertar o tom da tradução, reproduzindo aqui e agora as impressões que a leitura [de $O$ Decamerão] gerou séculos atrás" (2006d, p.50).

Apesar de adotar o critério da fidelidade para avaliar as traduções, ele entende que preservar todos os elementos do original é uma impossibilidade. Na coluna de julho de 2006, ele deixa transparecer essa ideia de que uma tradução completamente fiel ao texto original é uma utopia ao fazer um trocadilho com o título da obra de Thomas More: "As traduções brasileiras disponíveis procuram, em geral, estar à altura da sempre desejável e... utópica fidelidade ao texto original de Utopia" (Perissé, 2006c, p.61).

Talvez por isso, ele se preocupe em distinguir fidelidade de literalidade. Para ele, ser fiel é aproximar-se das intenções do autor do original; e ser literal consistiria em manter todos os termos do original. Diante da questão da literalidade das traduções, Perissé afirma que "[t]raduzir não se opõe a interpretar. A literalidade, afinal de contas, é desejo que nenhuma Fada [como a das Aventuras de Pinóquio] saberá atender" (Perissé, 2007f, p.59). Ou seja, para Perissé, uma tradução literal é desejável, ainda que a literalidade seja, em algumas situações, desaconselhável.

$\mathrm{Na}$ defesa de traduções fiéis, Perissé entende que a manutenção do estilo do autor é um desafio. Mas não se isenta de reprovar estratégias que prejudicam a preservação desse aspecto na tradução. Seu comentário sobre a tradução de Paulo M. Oliveira de que a 'escolha da locução 'a gente' confere ao texto um certo coloquialismo, não condizente com o estilo de Pascal" é um exemplo disso (Perissé, 2007c, p.62). Oliveira traduziu «Les Villes par où on passe on ne se soucie pas d'y être estimé » por "As cidades por onde passa, a gente não se importa de ser nelas estimados" (apud Perissé, 2007c, p.62). 
Nesse trabalho de crítica merece destaque o fato de ele sempre apresentar a transcrição de um trecho do original para ser cotejado com as suas traduções. Desse modo, Perissé permite que o leitor compare as traduções entre si e faça a sua própria avaliação das escolhas feitas por cada tradutor. Segundo ele, "o cotejo entre as traduções é apenas um exercício que ajudará o leitor a ser mais crítico com relação" a elas (Perissé, 2009b, por e-mail). E, de certo modo, à própria crítica, pois o leitor ganha maior autonomia para decidir se concorda ou não com as considerações feitas na coluna.

Entretanto, cabe aqui uma ressalva sobre o trabalho do crítico, pois a análise de apenas um trecho, apesar de oferecer a importante confrontação entre o original e sua tradução, contraria a recomendação de Reiss (2002), House $(1981,1997)$ e principalmente de Berman (1995) de que a comparação deve considerar o todo e não apenas excertos isolados da obra.

Mas Perissé faz declarações que demonstram que ele tem consciência das limitações dessa prática. No número 19 da revista, ele alerta o leitor para o caráter limitado da avaliação por meio desse cotejo pontual ao afirmar que os trechos selecionados - alguns verbetes de The devil's dictionary ( $O$ dicionário do diabo), de Gwinett Bierce ${ }^{\mathrm{ii}}$ - "para cotejar as duas traduções brasileiras são amostras que, de modo algum, servem como avaliações definitivas dos dois trabalhos, cada qual com seus méritos" (Perissé, 2007d, p.60). Em outras colunas, ele reconhece que cotejar apenas um trecho possibilita uma "brevíssima análise do trabalho dos tradutores" (Perissé, 2008a, p.56) ou uma "rápida análise dos três estilos tradutórios" (Perissé, 2008b, p.54).

Além disso, na coluna dedicada às traduções de Ask the dust, de John Fante, Perissé afirma que "[f]azer alguns comentários às duas traduções, comparando trechos de uma e outra, não significa opor uma a outra, elogiar esta e execrar aquela. Ambas dão aos leitores a chance de conhecer um clássico moderno da literatura norteamericana" (Perissé, 2007e, p.60).

Para Perissé, cotejar as versões das obras "é entrever o eterno conflito entre a fidelidade criativa e o risco da traição que há em todo trabalho de tradução" (Perissé, 2007f, p.59).

Infelizmente, o crítico centraliza a sua avaliação nesses trechos, fazendo poucos comentários que podem ser atribuídos à qualidade da tradução como um todo. Mas, é preciso reconhecer que uma análise mais extensa tornaria o trabalho do crítico impossível, principalmente considerando que a coluna é publicada mensalmente, em um espaço que vai de duas a no máximo quatro páginas por edição.

Apesar das limitações, a comparação entre as traduções garante um espaço em que podem ser melhor entendidas as diferenças de estilo entre os tradutores e outras diferenças, como as que decorrem de momentos históricos ou públicos-alvo diversos. Por exemplo, podem ser comparados os estilos de tradutores como Antonio Houaiss e Bernardina da Silveira Pinheiro, os dois primeiros tradutores de Ulysses, de James 
Joyce, para o português. Segundo Perissé, a tradução de Houaiss, "peca pelo intelectualismo, é cerebral, é rebuscada", enquanto a tradução de Bernardina, que é mais recente, "trabalha melhor a coloquialidade" e "opta por soluções diretas" (Perissé, 2005, p.58).

Esses comentários trazem para sua crítica uma observação acerca da influência exercida pela subjetividade dos tradutores no resultado de seus trabalhos, bem como a força de coerções exteriores, pois esclarecem que

pesava sobre os ombros de Houaiss a responsabilidade de realizar tradução de vanguarda, que satisfizesse os leitores e, de modo especial, os críticos (...). Bernardina, por outra parte, desde o início relacionou-se com o livro em nome de uma paixão profissional e pessoal (Perissé, 2005, p.58).

Além disso, com a comparação fica mais fácil perceber quando uma tradução mais recente se baseou ou se inspirou em outra que lhe é anterior, ou mesmo se houve um problema ético, como na denúncia que Perissé faz da tradução de Utopia apresentada em 2005 pela editora Rideel:

Preocupante é o caso da tradução da Editora Rideel (2005), atribuída a Heloisa da Graça Burati. Trata-se, na verdade, de uma cópia da tradução de Luiz de Carvalho Paes de Andrade, realizada no século 19, republicada (até então com os créditos verdadeiros) pela Athena Editora em 1973, pelas Edições de Ouro em 1966, pela Abril Cultural em 1972 (na coleção Os Pensadores) e pela Edipro em 1994 (Perrisé, 2006c, p.61).

Como pode ser percebido por esta breve descrição, mesmo que possam ser feitas ressalvas à coluna, é inegável que o trabalho de crítica desenvolvido por Gabriel Perissé na "Versão Brasileira" possui méritos no que tange às críticas de traduções literárias. Isso especialmente pela adoção de um posicionamento que leva os leitores a serem mais críticos em relação às traduções que leem.

\section{5) Conclusão}

Como visto, a questão da crítica de traduções é bastante complexa e desafiadora, uma vez que ainda há muito a ser estudado acerca da própria tradução e de sua prática; e isso inclui a questão da crítica das traduções produzidas em determinado contexto.

No caso do Brasil, a tradição de críticas de tradução é particularmente tímida, como pode ser percebido pelos exemplos descritos neste trabalho. A ausência de periodicidade é compensada pela qualidade dos trabalhos que foram desenvolvidos por 
Agenor Soares de Moura e Paulo Rónai, bem como pelo que tem sido feito por Gabriel Perissé.

Ainda assim, merece destaque o trabalho dos críticos aqui apresentados, principalmente porque a crítica veiculada fora do âmbito acadêmico é, provavelmente, a que provoca um maior impacto junto aos tradutores e ao público leitor de traduções; e também a que possibilita que a atividade da tradução saia da obscuridade e passe a ser não somente reconhecida, mas também valorizada por todos.

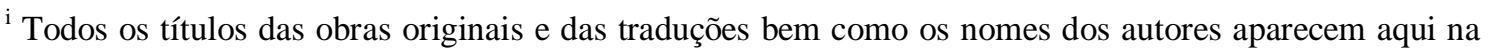
mesma forma que foi dada a eles por Gabriel Perissé na "Versão Brasileira".

${ }^{\text {ii } M a i s ~ c o n h e c i d o ~ c o m o ~ A m b r o s e ~ B i e r c e . ~}$
}

\section{Referências}

ARROJO, Rosemary. Oficina de tradução: a teoria na prática. 4 ed. São Paulo: Ática. 2005 .

BARROSO, Ivo (Org.). Nota do organizador. In: MOURA, Agenor Soares de. À margem das traduções. São Paulo: Arx, 2003. p.15-20.

BARILE, João Pombo. Agenor Soares de Moura tradutor. In: MINAS GERAIS Suplemento Literário. v.38, n. 1268, Belo Horizonte: UFMG, p.8-11, maio 2004. Disponível em: <http://www.letras.ufmg.br/websuplit/Lib/html/ webSupLit.htm>. Acesso em: 14 set. 2008.

BATTISTI, Patrícia Stafusa Sala. A crítica de tradução em Antoine Berman: reflexo de uma concepção anti-etnocêntrica da tradução. 2000. 129f. Dissertação (Mestrado). Instituto de Estudos da Linguagem, Unicamp, Campinas, 2000.

BENEDETTI, Ivone C. A crítica de traduções. Tradução em Revista. Rio de Janeiro: PUC-Rio; Publit, n. 2 Intervenções, p.69-75, 2005.

Tradução. Língua Portuguesa. n. 25. São Paulo: Editora Segmento, p.6. set. 2007. Seção Cartas.

BERMAN, Antoine. A prova do estrangeiro: cultura e tradução na Alemanha romântica. Trad. Maria Emília Pereira Chanut. Bauru: EDUSC, 2002.

A tradução da letra ou o albergue do longínquo. Trad. Marie-Hélène Catherine Torres, Mauri Furlan e Andréia Guerini. Rio de Janeiro: 7Letras /PGET, 2007. 
BRITTO, Paulo Henriques. Fidelidade em tradução poética: o caso Donne. In: Terceira margem X (15), p. 239-254, jul/dez. 2006.

CARDOZO, Mauricio Mendonça. Solidão e encontro: prática e espaço da crítica de tradução literária. 2004. 174f. Tese (Doutorado). Faculdade de Filosofia, Letras e Ciências Humanas, Universidade de São Paulo, São Paulo, 2004.

Espaço versus prática da crítica de tradução literária no Brasil. Cadernos de Tradução. v. 19, UFSC, 2007. Disponível em: <http://www.cadernos.ufsc.br/ online/volume19.html>. Acesso em: 17 nov. 2007.

ECO, Humberto. Quase a mesma coisa. Trad. Eliana Aguiar; revisão técnica de Rafaella Quental. Rio de Janeiro: Record, 2007.

HOUSE, Juliane. A model for translation quality assessment. Tübingen: Narr, 1981.

MOURA, Agenor Soares de. À margem das traduções. São Paulo: Arx, 2003.

PAES, José Paulo. Sobre a crítica de tradução. In__: Tradução: a ponte necessária aspectos e problemas da arte de traduzir. Série Temas. v. 22 Estudos Literários. São Paulo: Ática, 1990. p. 109-118.

PERISSÉ. Gabriel. De Ulysses a Ulisses. Língua Portuguesa. São Paulo: Editora Segmento, n.3, p.58-60, dez. 2005.

.Garimpeiro de idiomas. Língua Portuguesa. São Paulo: Editora Segmento, n.7, p. 58-60, maio 2006a.

Balzac em dois tempos. Língua Portuguesa. São Paulo: Editora Segmento, n.9, p. 56-58, jul.2006b.

Tradução de uma utopia. Língua Portuguesa. São Paulo: Editora Segmento, n.10, p.58-61, ago. 2006c.

.Boccaccio e uma centena de histórias. Língua Portuguesa. São Paulo: Editora Segmento, n.11, p.48-51, set. 2006d.

Traduções pelo espelho. Língua Portuguesa. São Paulo: Editora Segmento, n.14, p.62-64, dez. $2006 \mathrm{e}$.

A loucura do traduzir. Língua Portuguesa. São Paulo: Editora Segmento, n.15, p.60-62, jan. 2007a.

Traduções platônicas. Língua Portuguesa. São Paulo: Editora Segmento, n.17, p. 58-61, mar. 2007b. 
.Razão e corações traduzidos. Língua Portuguesa. São Paulo: Editora Segmento, n.18, p.60-62, abr. 2007c.

. Uma tradução infernal. Língua Portuguesa. São Paulo: Editora Segmento, n.19, p.58-60, maio 2007d.

.Um clássico norte-americano. Língua Portuguesa. São Paulo: Editora Segmento, n.20, p. 58-60, jun. 2007e.

Peraltices com Pinóquio. Língua Portuguesa. São Paulo: Editora Segmento, n.22, p. 58-59set, $2007 f$.

.Traduções assustadoras. Língua Portuguesa. São Paulo: Editora Segmento, n.25, p.48-50, nov. $2007 \mathrm{~g}$.

.Ventos uivantes da tradução. Língua Portuguesa. São Paulo: Editora Segmento, n.28, p. 54-57fev. 2008a.

.O eterno anjo azul. Língua Portuguesa. São Paulo: Editora Segmento, n.32, p.52-55, jun. 2008b.

A imaginação insaciável de Borges. Língua Portuguesa. São Paulo: Editora Segmento, n.37, p.56-57, nov. 2008c.

- Traduções maquiavélicas. Língua Portuguesa. São Paulo: Editora Segmento, n.38, p.57-59 dez. 2008 d.

.Entrevista. [mensagem pessoal]. Mensagem recebida por <regysane@hotmail.com>em 14 jan.2009b.

REISS, Katharina. Translation criticism - the potential \& Limitations: categories and criteria for translation quality assessment. Translated by Erroll F. Rhodes. Manchester, UK: St. Jerome Publishing, 2000.

RÓNAI, Paulo. Escola de tradutores. 5 ed. Rio de Janeiro: Nova Fronteira, INL, 1987.

Um tradutor. In: Moura, Agenor Soares de. À margem das traduções. São Paulo: Arx, 2003.

SCHLEIERMACHER, Friedrich. Sobre os diferentes métodos de tradução. Tradução de Margarete von Mühlen Poll. In: __ HEIDERMANN, Wener (org.). Clássicos da Teoria da Tradução - Antologia Bilíngüe. Vol. I Alemão-Português. CCE-DLLE Núcleo de Tradução, Universidade de Santa Catarina, 2001.

SHUTTLEWORTH, Mark; COWIE, Moira. Dictionary of Translation Studies. Manchester, UK: St. Jerome Publishing. 1999. 
SILVA, Francisco de Fátima da. A des-construção da crítica (literária) da tradução: uma análise das resenhas críticas de tradução do caderno MAIS! 2001. 97p. Tese (Doutorado). Unicamp. Disponível em: http://libdigi.unicamp.br/ document /?code=vtls000239976. Acesso em: 23 jan. 2008.

WYLER, Lia. Lia Wyler. In: Ivone Benedetti e Adail Sobral (Orgs.). Conversa com tradutores: balanços e perspectivas da tradução. São Paulo: Parábola, 2003. p.191-200. Entrevista.

VENUTI, Lawrence. A invisibilidade do tradutor. Tradução de Carolina Alfaro. Palavra. PUC-Rio: Rio de Janeiro, n.3, p.111-134, 1995a.

$\overline{1995 b}$

The translator's invisibility: a history of translation. London: Routledge, 